\title{
Надо верить в себя и много работать, и тогда все получится
}

\author{
Рассказывает технический директор ООО "Остек-Электро»
} А. Ю. Насонов

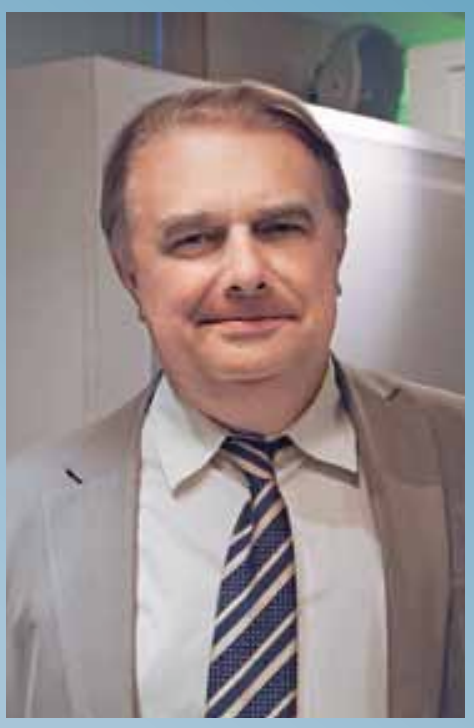

\author{
Компания "Остек-Электро» - одно из подразделений \\ Группы компаний Остек - занимается технологическим \\ оснащением процессов измерений, контроля, \\ тестирования и настройки в производстве электронной \\ техники. Свои задачи компания решает не только \\ как интегратор, подбирающий, поставляющий \\ и запускающий оборудование; в ее активе - целый \\ ряд приборов и установок собственной разработки, \\ многие из которых не имеют мировых аналогов. \\ Чтобы понять, как компания нашла свою нишу на \\ рынке, заполненном разнообразным оборудованием \\ от именитых и не очень известных производителей, \\ и узнать, как сегодня обстоят ее дела, мы договорились \\ о беседе с техническим директором ООО «Остек- \\ Электро» Андреем Юрьевичем Насоновым.
}

Андрей Юрьевич, что привело вас к решению дополнить деятельность компании в качестве поставщикаинтегратора разработкой и производством оригинальных приборов, что связано с ростом объема работы и к тому же с немалой долей риска?

Конечно, закупать и устанавливать готовое проще и спокойнее. Но практика показала, что ограничиться этим не удается: в промышленности сложилась очень тяжелая ситуация, связанная с острым недостатком технологического, измерительного, контрольного оборудования нужного уровня. Мы начали с небольших доработок импортных приборов и постепенно, почти незаметно для себя, превратились в разрабатывающую и производящую компанию, способную создавать изделия, не имеющие мировых аналогов.

Но почему так? Плохо ли это или хорошо, но наша электронная промышленность до сих пор опиралась на производственную базу, представленную преимущественно оборудованием зарубежного производства...

Действительно, долгое время технологическое переоснащение предприятий, в том числе и в части измерительной техники, базировалось на использовании импортного оборудования. Объяснялось это реальным отсутствием новых отечественных приборов, усиленным уверенностью в том, что западные компании "впереди планеты всей", и нечего нам пытаться сделать что-то свое.

Сегодня уже и не очень понятно, как образовалась эта уверенность. В 1990-е годы, когда всё рушилось, я имел доступ к достаточно большому кругу информации. И, тем не менее, тоже поверил в наше "отставание на полвека". Теперь понимаю: это не было правдой. Зададим себе вопрос: если к 1990 году СССР уже отставал на полвека, если потом еще лет 20 шли только деградационные процессы, как смогла страна сегодня показать столь высокий технологический уровень, скажем, в оборонной технике, и не только в ней? Понимая длительность реализации проектов такой сложности, могу с уверенностью сказать, что основы того, что Россия показала в 2010-х годах, были заложены именно в 1980-х и 1990-х. Значит, в некоторых областях, самых критичных, самых ответственных, развитие не остановливалось. Теперь очевидно, что значимого отставания не было, а о фатальном не стоит и говорить.

Получается, что разработчики, производственники как-то справлялись со своими задачами и на импортном оборудовании, и, наверное, на старом, еще советском. Почему же теперь этого стало не хватать?

Создание электроники высокого технического уровня в 1990-2000-е годы, конечно, было связано 
с большими проблемами, с которыми, однако, так или иначе справлялись. Но жизнь не останавливается. Да, там, где было очень нужно, мы смогли удержаться на должном уровне; но ведь надо двигаться вперед. Кроме того, в последние годы поставлены и начинают решаться задачи по общей модернизации промышленного комплекса страны, а это значит, что потребность в современной высокотехнологичной электронике вышла за рамки нескольких узких областей применения. Сейчас наблюдается активный рост заказов, необходимость в увеличении объемов производства при повышении внимания заказчиков к качеству продукции.

Все это привело к качественным изменениям в электронной отрасли; можно сказать, что она начала работать всерьез. Естественно, это потребовало нового технологического перевооружения, и тут выяснилось, что в области измерений, контроля, испытаний у нас далеко не всё в порядке по целому ряду причин.

\section{Что это за причины?}

Во-первых, то, о чем мы уже говорили: импортное измерительное оборудование часто не способно справиться с требованиями, которые предъявляют новые разработки отечественных КБ, новая продукция отечественных заводов. И дело не в санкциях, не в том, что нам чего-то не показывают, не продают. Дело именно в недостаточно высоком техническом уровне представленных на рынке приборов и установок.

В мире есть много производителей средств измерения. Они делают хорошие приборы, имеющие приемлемые метрологические характеристики для производства обычной массовой электроники. Когда же речь заходит о прецизионной технике, о точных измерениях, рынок начинает резко сужаться, и оказывается, что мировые производители мало что могут представить для таких задач

Приведу пример. К нам обратилась одна известная российская компания, ей потребовался прибор для контроля силовых супрессоров - полупроводниковых ограничителей напряжения. Мы честно попытались найти требуемое оборудование на рынке. Нашли: с некоторой натяжкой задачу могла выполнить американская установка весом более 300 кг с временем подготовки кединичному измерению 30 с и заоблачной стоимостью. И мы взялись разработать прибор сами, и сделали целую линейку генераторов Г6-51/X из восьми модификаций с разными параметрами импульсов и мощностью до 15 кВт. Наш прибор весит не более 25 кг, время готовности к измерению - 1 с.

Кстати, об отечественной элементной базе. В генераторе использованы конденсаторы емкостью 40 мкФ с допустимым током разряда 4000 А - такой ток может испарить солидный металлический болт. А выпускаться они начали еще в начале 1970-х годов! У американцев до сих пор нет аналогичных изделий.

\section{То есть у них таких конденсаторов нет и никогда не было?}

судя по всему, именно так. Мы их специально искали.

Вообще, комплектация наших приборов включает изделия самого разного происхождения. Там есть и вполне современные, в том числе зарубежного производства; но критичные компоненты, которые задают важнейшие характеристики, обычно отечественные, причем часто они созданы еще в Советском Союзе.
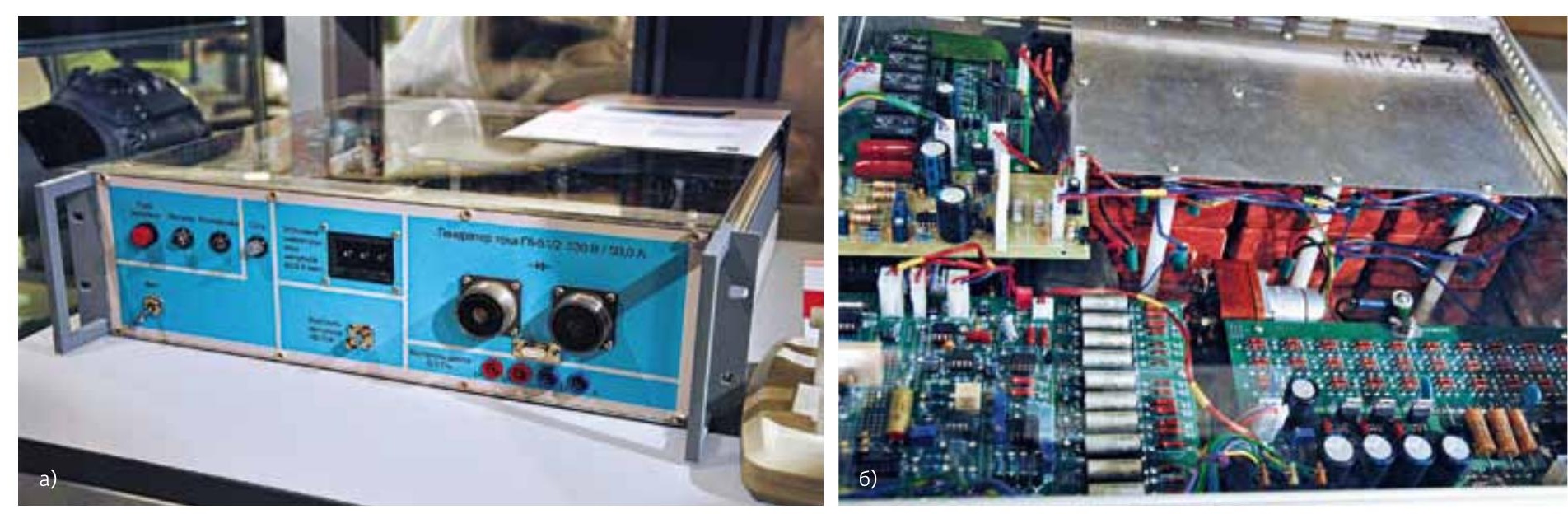

Генератор импульсов тока Г6-51/2 - одна из восьми моделей линейки Г6-51/X, предназначенной для испытания защитных приборов мощными импульсами тока: а - общий вид выставочного образца; 6 - под панелью у задней стенки корпуса можно видеть группу конденсаторов с максимальным током разряда 4000 A 
Вы всегда стараетесь использовать отечественную комплектацию?

Нет, в этом вопросе мы исходим из другой посылки: берем то, что лучше. Именно лучше, так как российское не всегда бывает дешевле импортного. Те же супрессоры, о которых мы говорили: отечественные стоят дороже, чем американские. Только американские выходят из строя там, где наши работают. А еще они проходят индивидуальный контроль, и производитель готов выписать паспорт на каждый экземпляр. Для тех потребителей, которые выпускают особо ответственную продукцию очень высокой стоимости, это имеет значение.

Вы сказали, что причин тяжелого положения в области измерительной техники несколько, а объяснили пока только одну.

Вторая причина - ужасающее состояние нашей системы метрологии. Измерительные средства, в основном иностранные, вносятся в Государственный реестр. Однако, когда посмотришь соответствующие документы... Иногда возникает впечатление, что прибор внесен в реестр чуть ли не по весу. А если серьезно, то вот одно из типичных нарушений: прибор вносится в реестр в некотором ограниченном диапазоне характеристик, в то время как информационные материалы фирмы-производителя рисуют другую, куда более оптимистичную картину. Понятно, что пользователь может столкнуться, мягко говоря, с существенными проблемами: результаты измерения параметров его изделий могут попросту оказаться недостоверными.

Мы решаем эту проблему. Все наши измерительные средства подвергаются полноценной метрологической экспертизе, и заказчик получает аттестованные приборы, внесенные в Госреестр. Они записываются в его Технические условия, они являются необходимым инструментом в процессе приемки заказчиком.

Третья причина - то, о чем уже говорилось выше: создаются совсем новые технологии, новая техника с характеристиками, которые раньше были недостижимы.

Опять можно вспомнить о супрессорах. Первое, что сделали заводчане, получив наши приборы, - испытали на них импортные супрессоры на соответствие требованиям их собственных ТУ. Ни один из них не выдержал тестирования! Сгорели все! А с супрессорами, изготовленными на этом заводе, всё в порядке. Производители улыбаются: видимо, перестарались. Ведь они начинали разработку, не имея таких средств измерения, и, получается, сделали конструкцию с запасом, который они оценивают как двукратный.

Перестарались они или нет, но факт налицо: нашим КБ и заводам удается наладить серийное производство изделий такого уровня, который недоступен ведущим западным производителям. Так откуда же у них, у западных, возьмется оборудование, способное произвести качественный контроль таких изделий?

Резюмируя, можно сказать, что на сегодня в стране сформировалась потребность в создании оригинальных измерительных, испытательных, контрольных приборов. Их надо производить самим, заграница тут не поможет. И мы это и делаем - изготавливаем специфическое, ни на что не похожее оборудование, причем именно для применения в серийных производствах. И, что очень важно, не отказываемся от доработки наших приборов, если у потребителя появились новые требования, например, в связи с освоением нового изделия.

Хорошо бы еще вложить понимание необходимости собственных разработок в головы некоторых чиновников, в которых до сих пор сидит стереотип, по которому технологическое переоснащение заключается в выборе западных компаний, у которых надо купить технику, да еще по возможности не последнего поколения - чтобы подешевле.

\section{Каким образом потенциальные заказчики узнают о ваших возможностях?}

До сих пор основным средством нашего продвижения остается "сарафанное радио". Приезжают люди обсудить заказ, спрашиваешь: как вы о нас узнали? В ответ: есть знакомый, работает на таком-то предприятии, он посоветовал обратиться, сказал - эти не подведут.

Очень много работ мы ведем, являясь соисполнителями в ОКР других предприятий. Ведь ОКР на разработку, скажем, нового типа резисторов подразумевает и проект технологической линии по их изготовлению, в том числе необходимого комплекта контрольноизмерительной аппаратуры. Имеющаяся экспериментальная, измерительная база, как правило, для новых разработок не подходит, ведь их целью является получение каких-то предельных, ранее не достигнутых характеристик. Вот и возникает потребность в соисполнителе - разработчики резисторов не знают, как организовать качественные измерения, это не их профиль. А негативного опыта более чем достаточно: желающие поучаствовать в ОКР появляются, только вот интересуются они прежде всего размером предоплаты, а про согласование Т3 им приходится напоминать. Можно понять, почему заказчики удивляются, когда мы через пять месяцев поставляем им прибор, уже внесенный в Госреестр. А у “сарафанного радио» появляется еще один источник информации.

\section{Правильно ли будет сделать вывод, что вы работае- те только по заказу?}

Нет, это не так. Мы же знаем рынок, бываем на многих предприятиях. Некоторые работы мы начинаем, увидев проблему, у которой пока нет хорошего решения. 

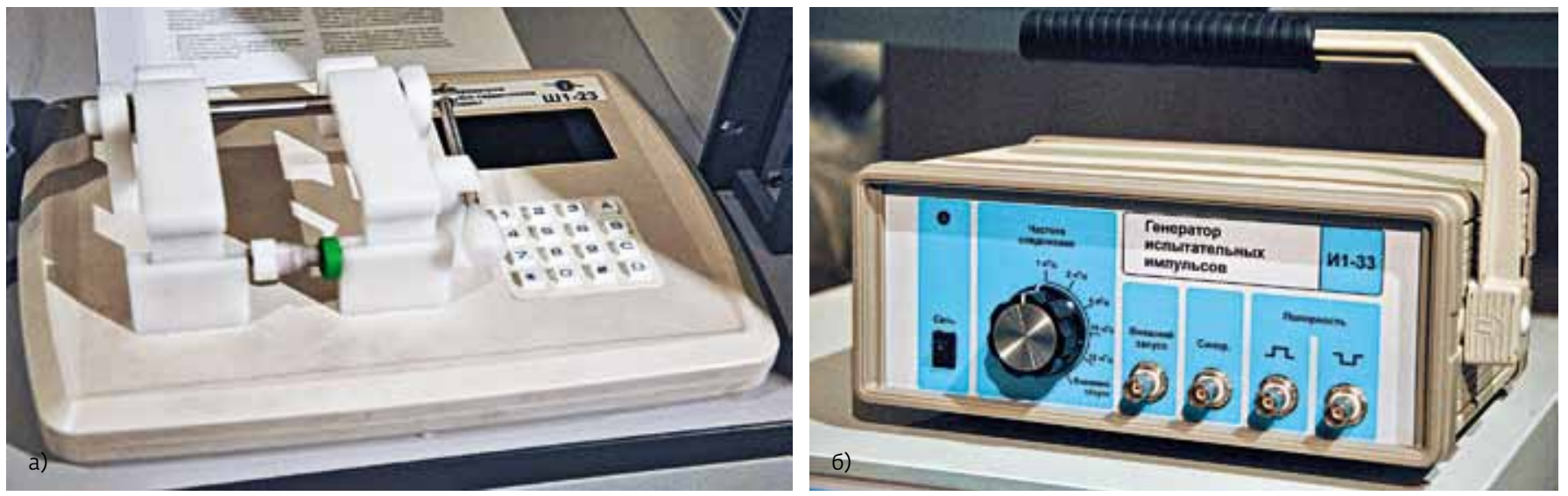

Разработано по собственной инициативе: а - измеритель параметров ферритовых сердечников кольцевой формы ш1-23; 6 - генератор испытательных импульсов И1-33

Один из примеров - Ш1-23, измеритель параметров ферритовых сердечников кольцевой формы. Мы взялись за его проектирование по собственной инициативе, выяснив, что у многих производителей возникают вопросы по контролю ферритовых сердечников и их подбору по характеристикам. На рынке присутствуют системы для этой цели, но они сложны, и стоимость их весьма высока. Мы же сделали недорогой компактный прибор, работающий по методу пробной катушки, но - и в этом наше ноу-хау - без необходимости намотки витков на эту катушку. Намотка - ручная операция, и ее исключение упрощает измерение и кратно уменьшает длительность всей операции. Про Ш1-23, который, по нашим сведениям, не имеет аналогов, можно без преувеличения сказать: он стал бестселлером.

Еще одна причина для оригинальной разработки недостатки оборудования, выявленные в ходе собственных работ.

Мы уже затрагивали вопрос о нынешнем состоянии метрологического обеспечения. Так вот, разбираясь с документами по метрологической аттестации импортной измерительной техники, мы обнаружили, что некоторые важнейшие характеристики осциллографов подтверждаются совершенно неприемлемым образом. Так, при аттестации скорости нарастания фронта импульса в качестве источника эталонного сигнала был применен генератор импульсов с параметрами чуть ли нехудшими, чем те, которые заявлены для самого осциллографа.

Как же проверить осциллограф? Стали искать - ничего подходящего нету. Пришлось взяться за дело самим, и мы создали генератор испытательных импульсов И1-33. Он довольно прост, но обеспечивает очень короткий (не более 100 пс) фронт импульсов и малую их длительность - 40 нс, обладает возможностями регулировки частоты следования, внешнего запуска и синхронизации.
Из сказанного можно понять, что такие изделия, как Ш1-23, вы можете, что называется, продавать со склада. А генераторы для проверки защитных приборов могут они стать таким продуктом?

Генераторы и близкие к ним по специфике приборы, наверное, всегда будут выпускаться как модификация под потребности конкретного заказчика. Причем не обязательно для разных потребителей; та же линейка из восьми модификаций, о которой мы говорили, сделана для одного завода, который выпускает супрессоры нескольких типов

Могут отличаться и эксплуатационные свойства. Например, на одном из предприятий после расширения производства возникла потребность в ускорении контрольных операций, и мы спроектировали Гб-52-пятиканальную модель, обеспечивающую автоматическую проверку пяти супрессоров в одном испытательном цикле.

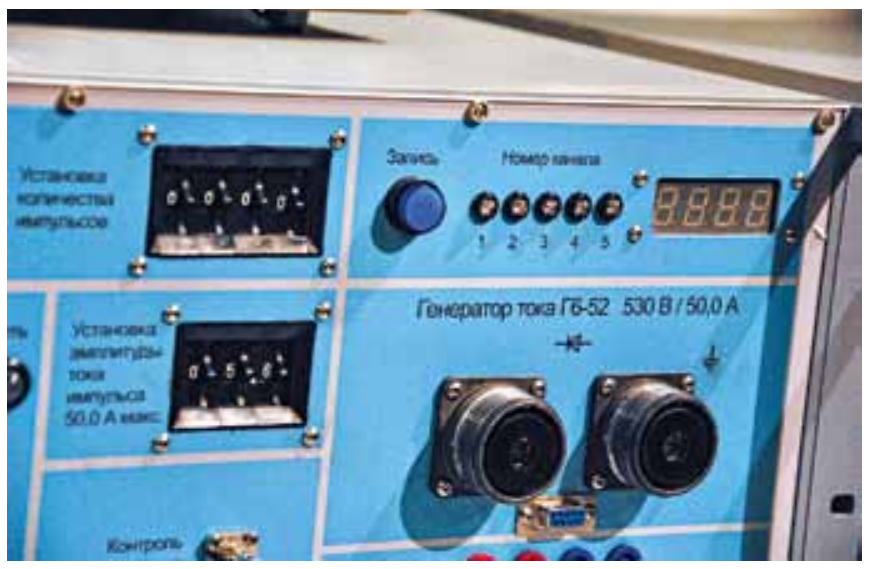

Фрагмент лицевой панели генератора Г6-52. В правой верхней части можно видеть линейку индикаторов, отображающих номер изделия, с которым в данный момент работает прибор 


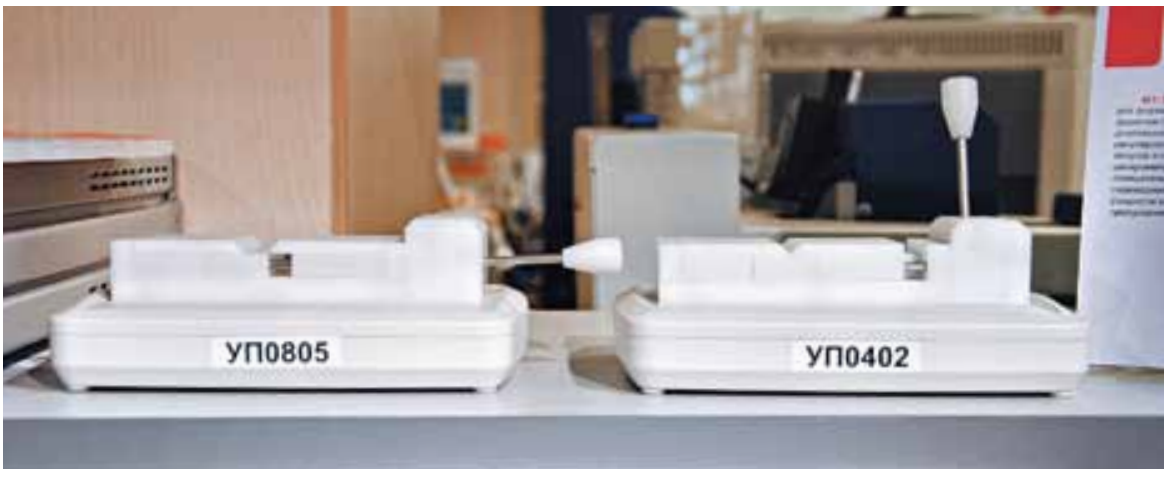

Адаптеры для рабочих мест измерения параметров компонентов

Адаптеры, несмотря на их кажущуюся простоту, достаточно сложны с конструктивно-технологической точки зрения. Скажем, SMD-резистор может иметь длину 2 мм и менее, а для организации четырехпроводной схемы к нему надо подвести по два щупа с каждой стороны, причем так, чтобы и резистор не повредить, и иголки у щупов не сломать. Наша конструкция гарантирует и точность измерения, и безопасность установки компонента. К тому же она более эргономична,

Измерительное оборудование применяется не только для проверки изготовленных изделий, но и на этапе входного контроля. Занимаетесь ли вы этой тематикой?

Разработки для входного контроля ЭКБ занимают значительное место в нашей деятельности. Только теперь, в соответствии с новым ГОСТом, применяется другое определение: верификация закупленной продукции. Такая корректировка обусловлена тем, что в современных реалиях в задачу этой процедуры входит не только отбраковка негодных изделий, но и выявление контрафакта.

В этой проблематике иногда обнаруживаются очень интересные вещи. Например: не всё то, что называют контрафактом, действительно является таковым. Оказывается, иные зарубежные производители таким образом пытаются прикрыть собственный брак - утверждают, что это не их продукция, а китайская подделка. Однако правдоподобность этого аргумента с каждым годом уменьшается, так как уровень качества продукции китайских производителей постоянно растет и во многих случаях уже превышает то, что предлагают рынку американцы.

Важно понимать, что входной контроль - это не просто аттестованные приборы, здесь нужны методики, стандарты. Во все это необходимо вникать, поскольку что-то устарело, а чего-то просто нет. Это большая работа, и мы, полагаю, достигли в этой области весьма высокого уровня компетентности.

Кстати, работая по этой тематике, мы тоже столкнулись с трудностями, которые породили целое направление собственных разработок. Речь идет об адаптерах, в которые устанавливаются проверяемые компоненты.

Взяв готовые адаптеры, мы увидели, что в них не реализуется полноценная четырехпроводная схема подключения к компоненту, позволяющая компенсировать сопротивление контактирующего устройства. Это означает, что они не способны обеспечить точность измерений. чем, скажем, распространенные на рынке контактирующие устройства для RLC-метров: от оператора требуется только положить компонент в рабочую область адаптера и повернуть рычаг - все перемещения деталей, необходимые для фиксации и контактирования, происходят за счет этого движения.

Мы предлагаем потребителям укомплектованные рабочие места со всеми необходимыми средствами измерения, инструментом для манипуляций с компонентами и целым набором адаптеров под различные виды корпусов и типоразмеры чипов - их может быть несколько десятков.

Это направление вашей деятельности - разработка и производство оригинальных устройств - является экономически эффективным?

Да, у нас устойчивый положительный баланс. И здесь надо сказать спасибо западным коллегам: они приучили российских покупателей к очень высокому уровню цен. Надо платить таможенный сбор, а тут еще санкции, то есть дополнительные риски. К тому же иногда на согласование поставки может уйти больше времени, чем мы затратим на разработку нужного прибора. Теперь уже многие потенциальные потребители в России знают, что мы можем предложить более простое, быстрое и качественное решение их задачи, чем доступное для них импортное оборудование.

Если уж заговорили о западных коллегах и эффективности... Общаясь с ними, мы имели возможность понять, как они добиваются высокой эффективности своего бизнеса. Не вдаваясь в детали, суть их подхода состоит в том, чтобы не делать ничего лишнего.

Простой пример. В советские годы перед изготовлением единичного экземпляра чего угодно, хоть табуретки, на него выпускался полный комплект КД. Это никому не было нужно - табуретка все равно делалась "на коленке», но таково было требование госТа. И этот стереотип до сих пор сохраняется у многих руководителей разных уровней. 
На Западе таких шаблонов нет, в организации производства они руководствуются здравым смыслом. С той же документацией: наблюдая постановку дела в одной немецкой компании, мы удивились тому минимуму КД, которым они обходятся. Компания выпускает прецизионные адаптерные системы, практически все заказы у нее единичные; можно себе представить, какой объем документации пришлось бы им готовить по нашему ГОСТу, сколько специалистов нужно было бы для этого. Как они справляются? Делают только то, что действительно нужно. Например, вся документация, которая поступает на рабочее место сборки кассеты адаптера "ложе гвоздей», файл сверловки. Остальное слесарь-сборщик знает и делает сам. Правда, он имеет квалификацию инженера.

Расскажете что-нибудь о последних разработках "Остек-Электро"?

Думаю, самая интересная из наших последних разработок - установка для входного контроля микросхем, находящихся в рабочем режиме, при температурах от -65 до 150 C. Установка, названная "Детерминал-Матрица», полностью, с нуля, разработана нами, изготовлена на нашем предприятии, и я нигде не видел ее аналогов.

Изготовленный экземпляр имеет четыре зоны тепла и четыре - холода. Они работают автономно, потому что мы с самого начала создавали систему как модульную: она может быть выпущена, скажем, в виде одного настольного модуля охлаждения.

\section{Охлаждение производится жидким азотом?}

Нет. Одна из главных “изюминок» системы состоит в том, что для охлаждения используется элемент Пельтье - кстати, производства одного из предприятий Санкт-Петербурга.

В нижней части каждого модуля находится тестовое оборудование, система управления холодильниками, нагревателями, вентиляцией, система дополнительного водяного охлаждения горячей стороны элемента Пельтье. На верхней поверхности расположена рабочая зона, куда помещается контролируемая микросхема в контактирующем устройстве. Замок герметичной крышки, закрывающей рабочую зону, - единственный механический узел зарубежного производства во всей установке.
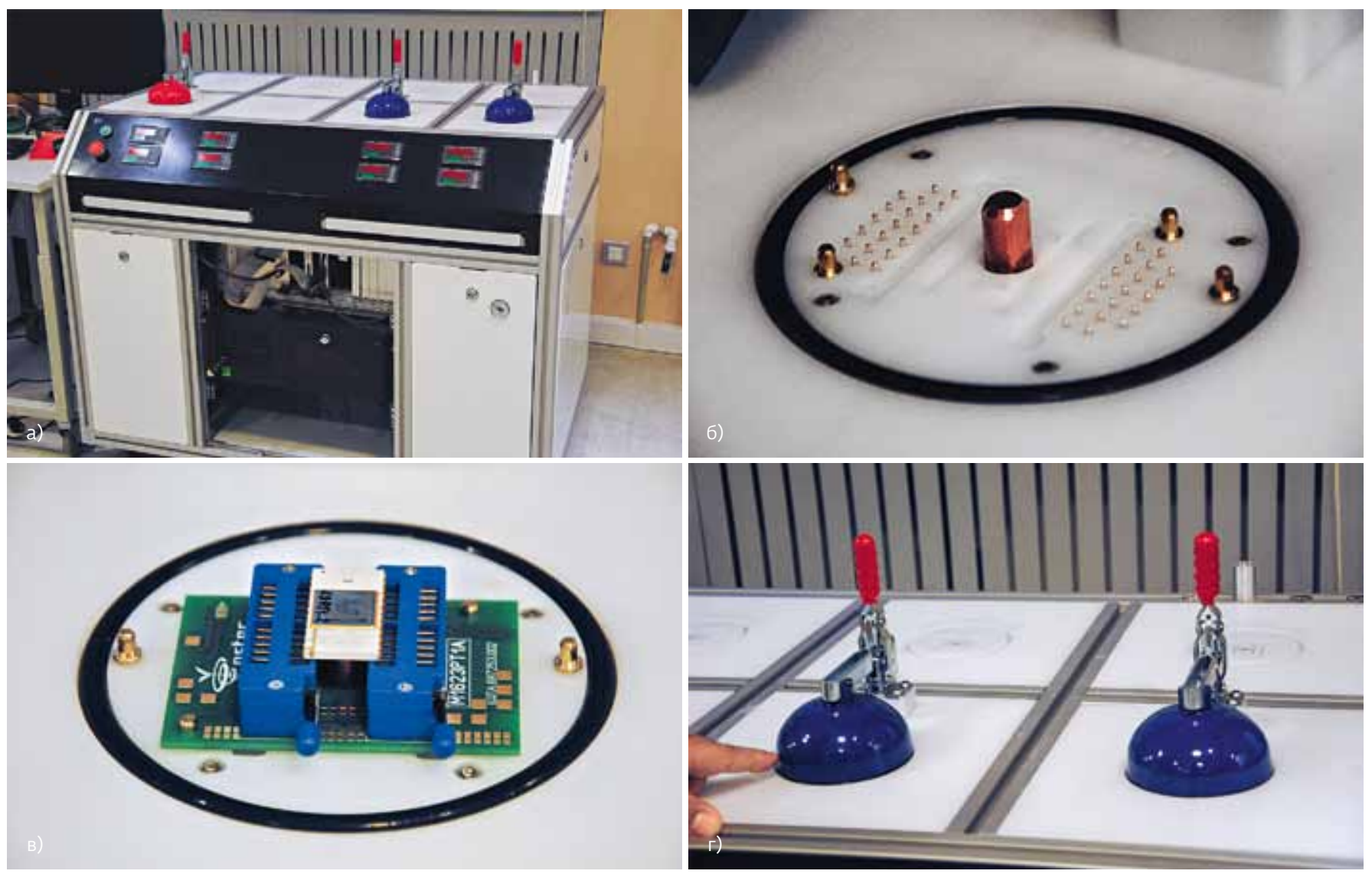

Система измерения электрических параметров ЭКБ под воздействием температуры "Терминал-Матрица": а - общий вид; 6 - рабочая зона; в - плата с контактирующим устройством и микросхемой; г - крышки закрыты, можно начинать процесс 
Контроль температуры осуществляется датчиком, прилегающим к нижней поверхности корпуса компонента.

Сразу после закрытия крышки включается компрессор, откачивающий из-под нее воздух; вакуум неглубокий, порядка 10 мм рт. ст., он нужен лишь для предотвращения образования росы. Включается охлаждение, и через 10 мин после закрытия крышки микросхема уже охлаждена до $-65^{\circ} \mathrm{C}$.

Сравните с обычной практикой, когда объект помещают в климатическую камеру и полдня ждут, пока она выйдет на нужный режим.

К тому же объект испытаний в камере связан с измерительным оборудованием жгутами двухметровой длины, а здесь все компактно...

Да, компактно, но все равно главной трудностью была именно отработка линии связи между измерителем и объектом. Для выполнения достоверных измерений необходимо, чтобы замеры соответствовали значениям стимулирующих и выходных сигналов непосредственно на выводах микросхемы, а не на входах измерителя, расположенного в недрах модуля. Длина связей составляет примерно 0,7 м, и на их согласование пришлось затратить очень много усилий.

Изготовленная установка предназначена для контроля микросхем определенной функциональной группы. Если нам будет заказана установка для контроля микросхем другого типа, или для другого класса компонентов, то, конечно, надо будет произвести определенные доработки, в частности, по функциям и составу тестового блока, по согласованию линий связи. Но мы теперь знаем, как надо это делать; а общая часть "начинки» модулей, так же как и ПО, в котором изначально предусмотрены элементы универсализации, уже хорошо отработаны.

В заключение вопрос, с которого, может быть, следовало бы начать: какими были ваши первые шаги в разработке?

Мы сами не ожидали, что будем разрабатывать собственные приборы. Начиналось все с небольших дополнений к закупленному оборудованию, изготовления простой оснастки. Первым большим изделием стал стенд для испытания сложной и весьма объемной кабельной продукции - в одном комплекте там были километры проводов, под две сотни разных разъемов. Процедура контроля выглядела очень громоздко, неудобно, и мы решили, что сделаем стенд для ее оптимизации.

Основу стенда составила спроектированная нами сборка стальных колонн с разъемами для подключения кабелей и индикаторами. Можно сказать, что решение взяться за такую крупную многоэлементную конструкцию было авантюрой - довольно быстро выяснилось, что мы не представляли себе и малой доли проблем, с которыми придется столкнуться. Но все же это была продуманная авантюра; по крайней мере, у нас было понимание, где будем заказывать ту или иную работу. Например, конструкцию колонн мы разработали с расчетом на технологии, которыми располагает одно из отделений ГК Остеккомпания "Гефесд".

Механическую сборку мы, как и собирались, выполнили сами, и тут случилось неожиданное: компания, которой мы намеревались заказать электрический монтаж, нам отказала по причине загруженности другими работами. Пришлось делать это самим, причем в экстренном порядке.

Мы совсем не были к этому готовы. В нашем распоряжении были только офисные помещения, никаких монтажников, естественно, в штате не было. Но отступать было поздно. Превратили офис в монтажный участок, паять научились даже девушки. Уборщицы недоумевали, видя в конце дня пол, засыпанный слоем снятой изоляции и обрезков провода...

Собрали, смонтировали, протестировали, перевезли к заказчику и в течение недели запустили в штатную эксплуатацию.

Конечно, по сравнению с тем, что мы делаем теперь, это была совсем простая система. Но тогда в головах людей произошло важнейшее изменение: они попробовали создать что-то свое, что-то такое, чего раньше не было, и у них получилось. Они открыли нечто новое в самих себе, новые возможности, новый интерес к работе. И поняли, что не надо бояться неизвестного, надо верить в себя, брать задачу, еще не зная, как будешь ее решать, и много работать - и тогда всё получится.

\section{И все-таки: вы взялись за этот проект по необходимо- сти, иначе не получили бы заказ? Или просто дерзну- ли, потому что захотелось большего?}

Да, именно так-захотелось большего. Знаете, мы ведь инженеры. Ахороший инженер, только разреши, быстро превратит офис в конструкторское бюро. Стать из посредника разработчиком, производителем - это совсем другой уровень мотивации. Другое самоощущение, совсем другие эмоции.

Теперь мы значительно выросли численно, появились необходимые подразделения, в том числе и производственные, сотрудники освоили необходимые знания и навыки, получили бесценный опыт практической работы. Сегодня мы загружены работой до такой степени, что поиск новых заказов совсем не является для компании приоритетной задачей.

Честно говоря, оглядываясь назад, я сам не совсем понимаю, как мы успели сделать так много...

Спасибо за интересный рассказ.

С А.Ю. Насоновым беседовап В. Е. Мейлищев 


\section{(1) ELEGTRON TECHEXPP}

Международная выставка

технологий, оборудования и материалов для производства изделий электронной и электротехнической промышленности

Ваш компонент успеха!

14-16 апреля 2020

Москва МВЦ «Крокус Экспо»

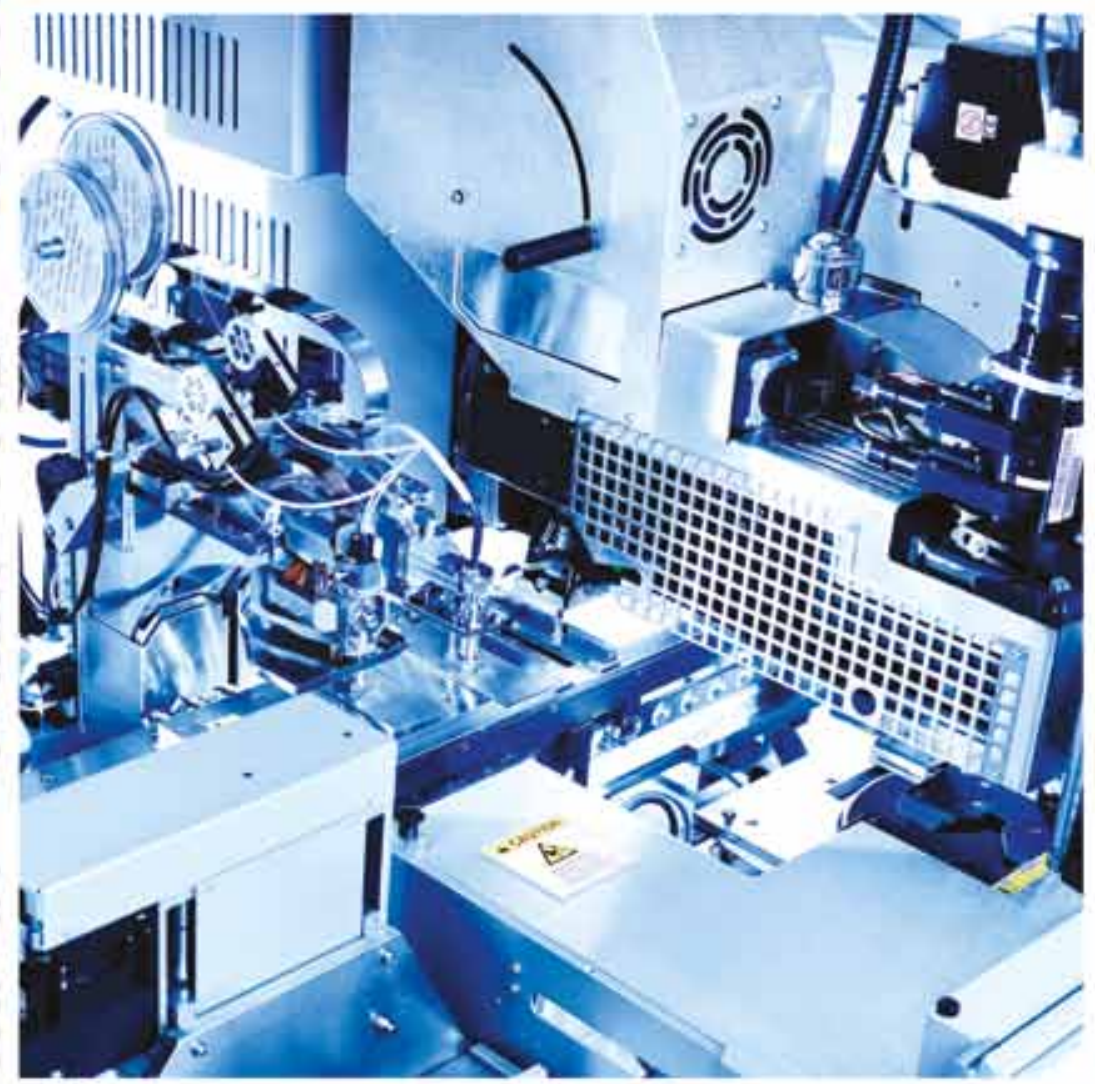

\section{Забронируйте стенд}

electrontechexpo.ru

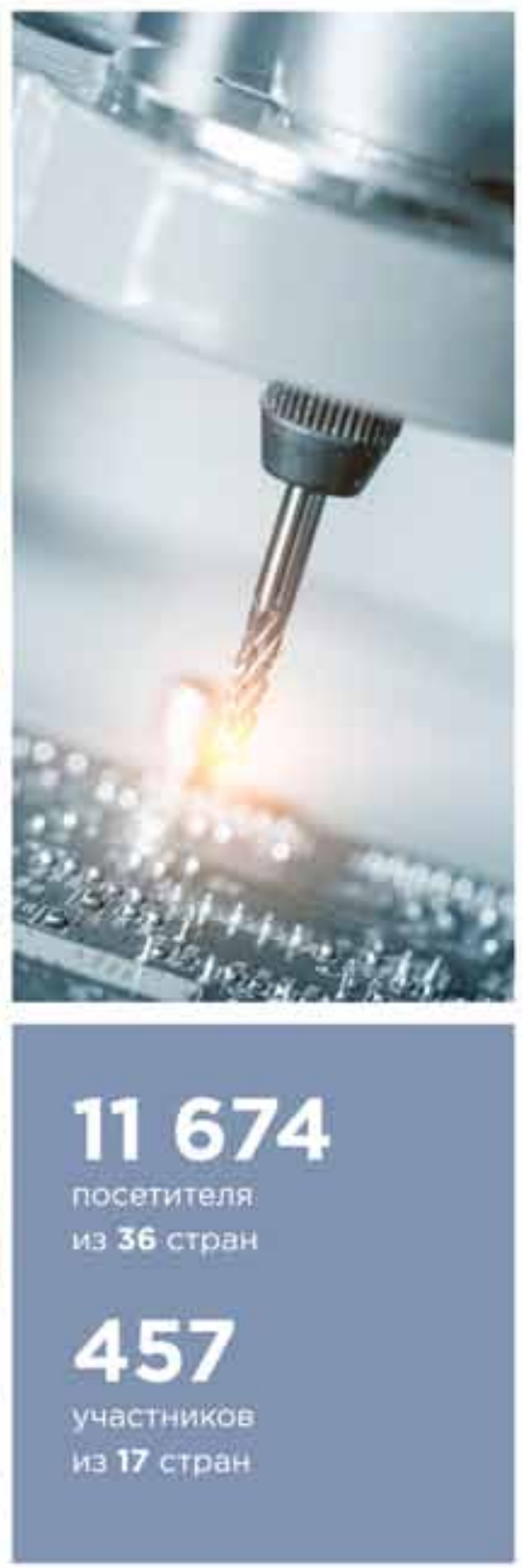

- Cosmectro c mactaenon

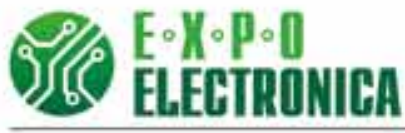

a Hywe even 


\section{КРЕМНИЕВЫЕ ЛАВИННЫЕ ФОТОДИОДЫ (функциональный аналог - фотодиоды ф. Hamamatsu)}

Кремниевые лавинные фотодиоды КОФ101Г, КОФ101Г1 работают в диапазоне длин волн, А, от 0,4 до 1,1 мкм. Диаметр активной области фотодиодов КОФ101Г, КОФ101Г1 - 80 мкм.

\section{Основные характеристики:}

- рабочее напряжение, U, порядка 180 B:

- максимум спектральной фоточувствительности, $\lambda \mathrm{s}$, от 0,82 до 0,88 мкм.

- козффициент умножения, M, порядка 60:

- чувствительность к световому потоку, $\mathrm{S}$, от 0,1 до 0,3 A/Bт.

\section{Область применения:}

- оптическая локация и дальнометрия;

- регистрация ионизирующих излучений;

- в качестве современной альтернативы фотоэлектронным умножителям.

Та6пица 1. Электрические параметры фотодиодов при Та $=25$ " $\mathrm{C}$

\begin{tabular}{|c|c|c|c|c|c|}
\hline \multirow{2}{*}{$\begin{array}{l}\text { Условное обозна: } \\
\text { ченме фотодиода }\end{array}$} & \multirow{2}{*}{$\begin{array}{c}\text { Наименование } \\
\text { nараметра, } \\
\text { единица измерения }\end{array}$} & \multirow{2}{*}{$\begin{array}{l}\text { Буквенное } \\
\text { обозначение }\end{array}$} & \multicolumn{2}{|c|}{ Hopma: } & \multirow{2}{*}{ Режим измерения } \\
\hline & & & He мeнeе & He Gonee & \\
\hline \multirow{3}{*}{$\begin{array}{l}\text { KOФ101Г } \\
\text { KOФ101Г1 }\end{array}$} & $\begin{array}{c}\text { Hanряжение } \\
\text { лавинного пробоя, В }\end{array}$ & $U_{s}$ & 140 & 200 & $I_{t}=100 \mathrm{MKA}$ \\
\hline & $\begin{array}{c}\text { Коэффициент } \\
\text { температурного } \\
\text { изменения напряжения } \\
\text { лавинного пробоя, B/"C }\end{array}$ & $k_{u r}$ & 0,8 & 2,5 & - \\
\hline & $\begin{array}{l}\text { Максимальный } \\
\text { темновой ток, А }\end{array}$ & $\mathrm{I}_{a}$ & - & $2 \cdot 10^{7}$ & $U=0,1 U_{b}$ \\
\hline КОФ101Г & \multirow{2}{*}{$\begin{array}{l}\text { Коэффициент } \\
\text { умножения }\end{array}$} & \multirow{2}{*}{$M$} & 30 & - & \multirow{2}{*}{$U=0,9 U_{0}+U_{6}$} \\
\hline KOФ101Г1 & & & 60 & - & \\
\hline $\begin{array}{l}\text { KOФ101Г } \\
\text { KOФ101Г1 }\end{array}$ & $\begin{array}{c}\text { Чувствительность K } \\
\text { световому потоку, А/BT }\end{array}$ & $\mathrm{S}$ & 0,1 & 0,3 & $\begin{array}{c}U=0 B \\
M=1, \lambda=\lambda\end{array}$ \\
\hline
\end{tabular}

Табпица 2 Предепьно допустимые значения электричесіих режимов экплуатации фотодиодов

\begin{tabular}{|c|c|c|}
\hline $\begin{array}{c}\text { Наименование режима sксплуатации, } \\
\text { единица измерения }\end{array}$ & $\begin{array}{l}\text { Буквенное } \\
\text { обозначение }\end{array}$ & Норма \\
\hline Максимально допустимое напряжение, В & $U_{\max }$ & $U_{\text {, }}$ \\
\hline Максимапьно допустимый темновой ток, мА & $I_{\text {max }}$ & 1 \\
\hline
\end{tabular}

Таб̆лица 3. Cправочные аначеник алектрических параметров

\begin{tabular}{|c|c|c|c|}
\hline \multirow{2}{*}{$\begin{array}{l}\text { Наименование параметра, единица } \\
\text { измерения. режим измерения }\end{array}$} & \multirow{2}{*}{$\begin{array}{l}\text { Буквенное } \\
\text { обозначение }\end{array}$} & \multicolumn{2}{|c|}{ Норма параметра } \\
\hline & & He metree: & He бonee \\
\hline Емкость, $п \Phi, n р и U=0,1 U_{b} B$ & c & 2 & 40 \\
\hline Квантовая эффективность, $\%, \begin{aligned} \% & =\lambda, \\
M & =1\end{aligned}$ & QE & 50 & - \\
\hline Эквивапентная мощность шума, нВт & NEP & - & 20 \\
\hline Частота отсечки, МГц, при $R=1$ кОм & $t_{c}$ & 1 & 50 \\
\hline
\end{tabular}

Tабпица 4. Tопцина иристапла, технопотиеская маріировка, координаты технопотиескои маріировки

\begin{tabular}{|c|c|c|c|c|}
\hline \multirow{2}{*}{ Усповное обозначение фотодиода } & \multirow{2}{*}{$\begin{array}{l}\text { Tormunнa } \\
\text { ispucranna, MM }\end{array}$} & \multirow{2}{*}{$\begin{array}{l}\text { Texнолотическая } \\
\text { мapкировка }\end{array}$} & \multicolumn{2}{|c|}{$\begin{array}{l}\text { Координаты технопогической } \\
\text { маркировки (певый нижний угол) }\end{array}$} \\
\hline & & & X.MM & Y. MM \\
\hline КОФ101Г, КОФ101Г1 & $0,4 \pm 0,01$ & LFD & 0,66 & 0,69 \\
\hline
\end{tabular}



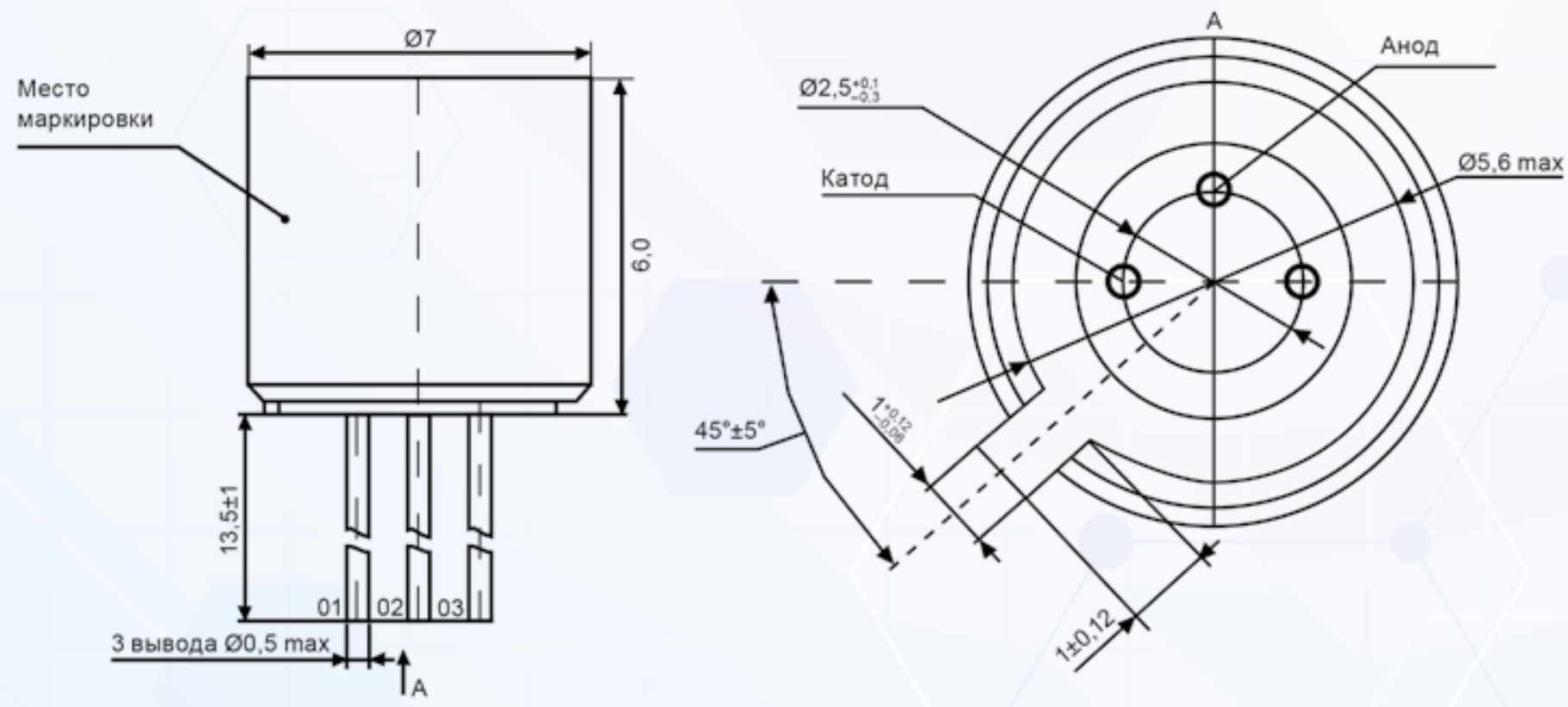

Рис. 2. Внешний вид кристалла

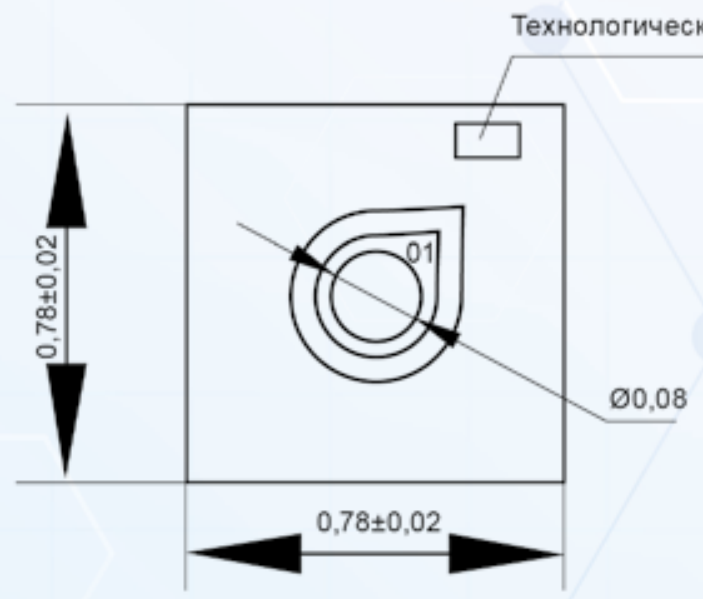

Таблица 5. Координаты контактных площадок

\begin{tabular}{|c|c|c|c|}
\hline \multirow{2}{*}{ Условное обозначение фотодиода } & \multirow{2}{*}{ Номер контактной площадки } & \multicolumn{2}{|c|}{$\begin{array}{c}\text { Координаты контактной } \\
\text { площадки (правый верхний угол) }\end{array}$} \\
\hline & & $\mathrm{X}, \mathrm{mm}$ & $\mathrm{y}, \mathrm{mm}$ \\
\hline \multirow{2}{*}{ КОФ101Г, КОФ101Г1 } & 01 & 0,461 & 0,461 \\
\hline & 02 & \multicolumn{2}{|c|}{ Обратная сторона кристалла } \\
\hline
\end{tabular}

Таблица 6. Состав и толщцина слоев металлизации

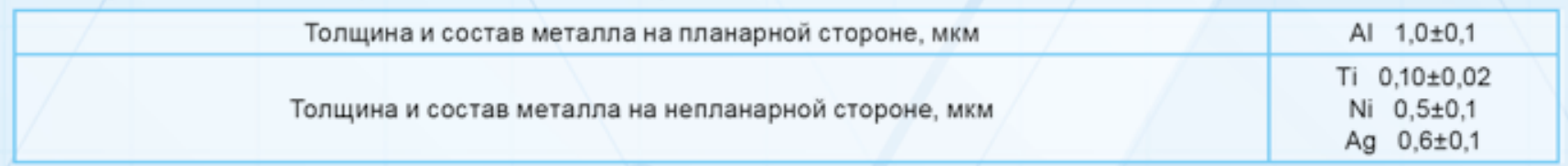

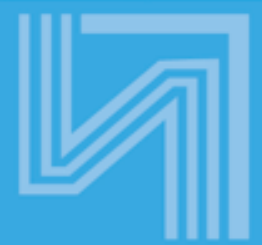

ОАО «ИНТЕГРАЛ» -

управляющая компания

холдинга «ИНТЕГРАЛ»

Республика Беларусь

E-mail: ATitov@integral.by 